VNU Journal of Science: Legal Studies

Journal homepage: https://js.vnu.edu.vn/LS

Review Article

\title{
Duty to Provide Information in Insurance Contracts in the Pre-Contractual Period
}

\author{
Bach Thi Nha Nam* \\ University of Economics and Law, Ho Chi Minh City National University, \\ Quarter 3, Linh Xuan Ward, Thu Duc District, Ho Chi Minh City
}

Received 24 June 2020

Revised 06 September 2020; Accepted 26 September 2020

\begin{abstract}
The obligation to provide information in insurance contracts in the pre-contractual period is one of the fundamental factors to form an insurance contract. Before participating in insurance contract, the insurers mainly rely on the information provided by the prospective policyholder, to assess risks on the information provided, then decide whether or not to engage in an insurance contract. Concurrently, the responsibility to provide information on the precontractual period is not only set for the prospective policyholders, but also for the insurers in explaining the terms and the standard clauses of the insurance contract. In the article, the author analyzes the asymmetric information in insurance business and its interaction with the goodfaith principle, and presents the drawbacks of the current legal framework relating to duty to provide information in the insurance disputes in Vietnam.
\end{abstract}

Keywords: Insurance, obligation, good faith, information.

\footnotetext{
${ }^{*}$ Corresponding author.

E-mail address: nambtn@uel.edu.vn

https://doi.org/10.25073/2588-1167/vnuls.4303
} 


\title{
Trách nhiệm cung cấp thông tin trong hợp đồng bảo hiểm giai đoạn tiền hợp đồng
}

\author{
Bạch Thị Nhã Nam* \\ Đại học Kinh tế - Luật, Đại học Quốc gia Thành phố Hồ Chí Minh \\ Khu phố 3, Phuờng Linh Xuần, Quận Thủ Đức, Thành phố. Hồ Chí Minh \\ Nhận ngày 24 tháng 6 năm 2020 \\ Chỉnh sửa ngày 06 tháng 9 năm 2020; Chấp nhận đăng ngày 26 tháng 9 năm 2020
}

\begin{abstract}
Tóm tắt: Trách nhiệm cung cấp thông tin trong giai đoạn hợp đồng bảo hiểm là một trong những yếu tố nền tảng để hình thành việc giao kết hợp đồng bảo hiểm. Trước khi tham gia bảo hiểm, doanh nghiệp bảo hiểm $(\mathrm{DNBH})$ chủ yếu dựa vào những thông tin được cung cấp bởi bên dự định mua bảo hiểm, để đánh giá những rủi ro trên những thông tin được cung cấp, DNBH đi đến việc có thực hiện việc giao kết HĐBH hay không. Đồng thời, trách nhiệm cung cấp thông tin giai đoạn tiền hợp đồng không chỉ đặt ra đối với bên dự định mua bảo hiểm mà còn đối với DNBH trong việc giải thích các nội dung điều khoản của hợp đồng bảo hiểm đối với bên dự định mua bảo hiểm. Trong bài viết tác giả phân tích tính bất cân xứng thông tin trong quan hệ bảo hiểm và mối quan hệ với nguyên tắc trung thực, thiện chí, các quy định pháp luật liên quan đến trách nhiệm cung cấp thông tin trong hoạt động kinh doanh bảo hiểm ở giai đoạn tiền hợp đồng bảo hiểm và chỉ ra các bất cập của việc áp dụng quy định này trong thực tiễn tranh chấp bảo hiểm ở Việt Nam..
\end{abstract}

Tù khóa: Bảo hiểm, trách nhiệm, thiện chí, thông tin.

\section{Tính bất cân xứng về thông tin và mối quan hệ với nguyên tắc trung thực, thiện chí}

Hợp đồng nói chung, và hợp đồng bảo hiểm (HĐBH) nói riêng là sự thống nhất ý chí. Trong giai đoạn tiền hợp đồng trước khi tiến hành giao kết, thông tin có một vai trò rất quan trọng giúp cho các bên hiểu rõ hơn về những gì mỗi bên mong muốn khi giao kết hợp đồng. Trong quá trình đàm phán $\mathrm{HĐBH}$, cụ thể doanh nghiệp bảo hiểm $(\mathrm{DNBH})$ cần bên mua bảo hiểm $(\mathrm{BMBH})$ cung cấp các thông tin về đối tượng được bảo hiểm, để từ đó đánh giá, phân tích và đi đến kết luận có chấp nhận bảo hiểm hay không. Ngược lại, BMBH cần những thông tin về $\mathrm{HĐBH}$ để hiểu rõ hơn về các điều khoản trong $\mathrm{HĐBH}$, quyền và nghĩa vụ của mình,

\footnotetext{
* Tác giả liên hệ.

Địa chỉ email: nambtn@uel.edu.vn

https://doi.org/10.25073/2588-1167/vnuls.4303
}

cách xử lý khi có sự kiện bảo hiểm xảy ra hoặc những thông tin nào mà $\mathrm{DNBH}$ cần $\mathrm{BMBH}$ cung cấp.

Hợp đồng bảo hiểm là quan hệ chia sẻ rủi ro. Do đó, những hiểu biết về rủi ro là căn cứ chủ yếu để các bên cân nhắc, tính toán lợi ích, thỏa thuận và thể hiện ý chí của mình về việc có tham gia hay không tham gia hợp đồng, hoặc nếu tham gia thì ở mức độ, điều kiện như thế nào: mức phí bảo hiểm ra sao và các điều kiện bảo hiểm cụ thể là gì. Tính chất không rõ ràng của rủi ro tiềm ẩn một nguy cơ mà làm các bên dễ có cách hiểu khác nhau.

Khi hoạt động bảo hiểm trở nên ngày càng phổ biến, trong việc giao kết hợp đồng bảo hiểm, người ta đã ngày càng nhận ra rằng, quan hệ bảo hiểm mang một đặc thù là $\mathrm{DNBH}$ và BMBH không nắm giữ thông tin như nhau đối với những thông tin liên quan đến đối tượng được bảo hiểm, cần được đánh giá, dự đoán rủi ro. Việc thông tin bất cân xứng này, dẫn đến hệ 
quả bên mạnh thế, bên yếu thế trong hợp đồng bảo hiểm. Rủi ro là điểm nút của quan hệ bảo hiểm, vì vậy, những hiểu biết khác nhau về rủi ro tiếp đến tự nó sẽ ngăn cản thống nhất ý chí của các bên. Trong khi đó, nguyên tắc tự do ý chí - nguyên tắc pháp lý cơ bản nhất chi phối mọi loại hình quan hệ hợp đồng bao gồm cả quan hệ bảo hiểm - lại đòi hỏi hợp đồng phải là sự thống nhất ý chí thật của các bên tham gia. Như vậy, giữa tồn tại đặc thù của quan hệ bảo hiểm và nguyên tắc tự do ý chí phát sinh mâu thuẫn trái ngược nhau. Nhận thức về mâu thuẫn này, luật pháp các nước, nhằm đảm bảo sự tồn tại và vận hành thông suốt của nguyên tắc tự do ý chí, đã đưa ra giải pháp là phải lập lại trật tự nắm giữ lượng thông tin nhằm giúp cho sự bất cân xứng thông tin trở nên cân bằng hơn [1]. Đây cũng chính là cơ sở cho việc áp đặt, hình thành một nghĩa vụ mà theo đó $\mathrm{BMBH}$, trong mọi khả năng có thể của mình, phải cung cấp cho BMBH một cách đầy đủ và trung thực nhất những thông tin liên quan phục vụ việc dự đoán, đánh giá rủi ro trong giai đoạn tiền hợp đồng. Nghĩa vụ này được gọi là nghĩa vụ thiện chí, trung thực trong việc giao kết hợp đồng bảo hiểm.

Khoảng thời gian trước khi hợp đồng được xác lập được xem giai đoạn "tiền hợp đồng" và mục đích của giai đoạn tiền hợp đồng nhằm giúp các bên trao đổi các thông tin cơ bản và cần thiết về nội dung, đối tượng, mục đích của việc giao kết hợp đồng, xem xét khả năng giao kết hợp đồng, thương lượng những điều khoản nhất định và tạo những điều kiện cần thiết cho việc giao kết [2]. Nguyên tắc thiện chí, trung thực đã được pháp luật các nước đề cập đến trong giai đoạn tiền hợp đồng trong mối quan hệ thương lượng hợp đồng giữa các bên, liên quan đến việc trao đồi và cung cấp thông tin cơ bản cho nhau. Ngoài ra, nguyên tắc trung thực, thiện chí còn được áp dụng trải dài không chỉ trong suốt quá trình từ đàm phán, giao kết, mà còn trong quá trình thực hiện hay thay đổi, chấm dứt hợp đồng [3, 109].

Ở Việt Nam, nguyên tắc trung thực, thiện chí không được ghi nhận trong Pháp lệnh hợp đồng kinh tế năm 1989 và Pháp lệnh hợp đồng dân sự năm 1991. Đến Bộ luật Dân sự (BLDS) 1995, nguyên tắc "thiện chí, trung thực" đã chính thức được ghi nhận tại Điều 9 theo đó "trong hệ dân sự, các bên phải thiện chí, trung thực, không chỉ quan tâm, chăm lo đến quyền lợi ích hợp pháp của mình mà còn phải tôn trọng, quan tâm đến lợi ích của Nhà nước, lợi ích công cộng, quyền, lợi ích hợp pháp của người khác, giúp đỡ, tạo điều kiện cho nhau thực hiện quyền, nghĩa vụ dân sự, không bên nào được lừa dối bên nào; nếu một bên cho rằng bên kia không trung thực, thì phải có chứng cứ". BLDS 2005 cụ thể hóa bằng việc đưa ra nguyên tắc này trong trường hợp khi cá nhân, pháp nhân tham gia giao dịch dân sự [4]. Theo BLDS 2005, quy định về nguyên tắc thiện chí, trung thực như sau: "Trong quan hệ dân sư, các bên phải thiện chí, trung thưcc trong việc xác lập, thực hiện quyền, trách nhiệm dân sư, không bên nào được lì̀a dối bên nào." [5, Điều 6]. Ở BLDS 2005, pham vi điều chỉnh của nguyên tắc này được thể hiện cụ thể hơn, đó là việc các bên phải thiện chí, trung thực trong việc xác lập, thực hiện quyền, nghĩa vụ dân sự, qua đó có thể thấy rằng với quy định này, nguyên tắc thiện chí, trung thực không chỉ áp dụng trong việc thực hiện mà còn trong cả việc xác lập quyền, nghĩa vụ dân sự. Trên cơ sở kế thừa nguyên tắc này trong BLDS 2005 , trong BLDS 2015 cũng quy định các cá nhân, pháp nhân phải xác lập, thực hiện, chấm dứt quyền, nghĩa vụ của mình một cách thiện chí, trung thực [6, khoản 3, Điều 3].

Xét về nội hàm từ ngữ trong Tiếng Việt, thiện chí là ý định, suy nghĩ tốt và luôn thực lòng mong muốn đi đến kết quả tốt khi giải quyết việc gì [7]. BLDS 1995 còn chỉ rõ "thiện chí không chỉ quan tâm đến quyền, lợi ích hợp pháp của mình mà còn phải tôn trọng, quan tâm đến lợi ích hợp pháp của người khác" tại Điều 9. Còn trung thực là ngay thẳng thật thà, không làm cho sự việc sai khác đi so với bản chất. Nội dung cơ bản của nguyên tắc này trong giai đoạn tiền hợp đồng yêu cầu các bên phải tự nguyện cung cấp cho nhau những thông tin đầy đủ, trung thực liên quan đến việc giao kêt, đàm phán hợp đồng $[8,48$.]

Trên thực tế, việc một bên nắm rõ thông tin về đối tượng được bảo hiểm hơn bên còn lại là 
vấn đề phổ biến. BMBH, người nắm rõ nhất về tình hình của đối tượng được bảo hiểm và tiếp cận thông tin về rủi ro sẽ nhiều hơn so với bên DNBH. DNBH là bên biết rất ít thông tin về đối tượng được bảo hiểm thậm chí là không có thông tin nào về đối tượng được bảo hiểm hoặc rủi ro có thể xảy ra đối với đối tượng được bảo hiểm. Tuy nhiên, để DNBH quyết định được mức bảo hiểm phí là bao nhiêu, hoặc quyết định có bảo hiểm hay không, thì DNBH lại cần có đầy đủ thông tin để đánh giá, dự đoán đúng về rủi ro. Tùy theo mức độ của rủi ro mà $\mathrm{DNBH}$ sẽ đưa ra mức phí bảo hiểm cao hay thấp hoặc thậm chí không nhận bảo hiểm.

Cho nên sự nắm giữ thông tin một phía của $\mathrm{BMBH}$ đẩy $\mathrm{DNBH}$ vào một trong hai tình huống: nếu muốn đưa ra một quyết định bảo hiểm hợp lý và đảm bảo lợi ích chính đáng của mình, hoặc thư nhất, DNBH phải tự mình điều tra thông tin và gánh chịu những phí tổn cho công việc điều tra cũng như chấp nhận việc điều tra có thể không hoàn toàn chính xác và đầy đủ, hoặc thú hai, DNBH phải chịu sự lệ thuộc vào chia sẻ thông tin từ phía $\mathrm{BMBH}$, đồng thời cũng sẽ chịu luôn nguy cơ người mua bảo hiểm không cung cấp đủ các thông tin, từ đó người bảo hiểm sẽ đánh giá thấp rủi ro và đưa ra mức bảo hiểm phí thấp tương ứng hoặc thậm chí nhận bảo hiểm vượt quá khả năng của mình $[9,55]$. Cả hai tình huống trên đều gây bất lợi cho phía DNBH. Do đó, nếu không có một sự ràng buộc cụ thể về nghĩa vụ cung cấp thông tin, thì vấn đề mỗi bên tự nguyện cung cấp đầy đủ thông tin cho bên còn lại sẽ khó mà thực hiện tốt. Rõ ràng, trong lĩnh vực bảo hiểm, $\mathrm{BMBH}$ có $\mathrm{xu}$ hướng che giấu những thông tin có thể ảnh hưởng đến việc xác định phí bảo hiểm, hay việc trả tiền bảo hiểm của $\mathrm{DNBH}$, nên trong một số trường hợp nếu như không áp đặt một nghĩa vụ thì sẽ ảnh hưởng đến sự công bằng trong $\mathrm{HĐBH}$.

Mặc dù việc thông tin bất cân xứng trong quan hệ bảo hiểm thường nghiêng về $\mathrm{BMBH}$, nhưng trên thực tiễn có những thông tin mà DNBH không cung cấp, không giải thích những nội dung, điều khoản trong $\mathrm{HĐBH}$ cho $\mathrm{BMBH}$. Do vậy, nếu như nghĩa vụ trung thực, thiện chí được áp đặt lên mỗi $\mathrm{BMBH}$ thì ngược lại,
DNBH cũng có nghĩa vụ tương ứng trong giai đoạn tiền hợp đồng.

Nghĩa vụ trung thực, thiện chí trong bảo hiểm lần đầu tiên được đề cập trong một án lệ về bảo hiểm ở Anh trong vụ Carter và Boehm vào năm 1766 [10]. Trong vụ án này thẩm phán Lord Manfield đã đưa ra phán quyết rằng: " $B a ̉ o$ hiểm là môt hợp đồng dựa trên sư suy đoán, thiên chí. Cấm các bên che giấu nhũng gì mà biết, nhằm làm cho bên còn lại hiểu sai về thưc tế." Hiện nay, nội dung cơ bản của nguyên tắc trung thực thiện chí ở các nước đều yêu cầu các bên khi giao kết hợp đồng bảo hiểm phải cung cấp cho nhau một cách tự nguyện, đầy đủ và trung thực đối với những thông tin giúp đánh giá, dự đoán rủi ro. Đạo luật bảo hiểm hàng hải của Anh 1906 quy định về nguyên tắc trung thực, thiện chí như sau: "Người mua bảo hiểm phải tiết lộ cho nguời bảo hiểm mọi thông tin quan trọng được biết đến bởi nguời mua bảo hiểm, và người mua bảo hiểm được coi là biết đến moi thông tin nếu trong quá trình hoạt đọng kinh doanh bình thuoòng của mình, anh ta phải biết về thông tin đó, mọi thông tin được coi là quan trọng nếu nó ảnh huởng tới đánh giá của một người bảo hiểm khôn ngoan trong việc định mức bảo hiểm phí, hoặc quyết định liệu có chấp nhận rủi ro hay không" [11].

Đối với nghĩa vụ trung thực, thiện chí của DNBH trong việc cung cấp thông tin cho $\mathrm{BMBH}$, Luật bảo hiểm của Pháp quy định nội dung cụ thể: "người bảo hiểm phải tiết lọ chính xác, thời điểm hợp đồng được hình thành, tất cả các truoòng hợp trong kiến thức của mình có thể ảnh hường tới nhận thức của ngưòi mua bảo hiểm về rủi ro" [12, Điều 172].

\section{Trách nhiệm cung cấp thông tin trong pháp luật bảo hiểm Việt Nam}

Trách nhiệm cung cấp thông tin trong kinh doanh bảo hiểm được du nhập vào Việt Nam và được ghi nhận lần đầu tiên trong hệ thống pháp luật bảo hiểm của Việt Nam vào năm 1990 tại Điều 204, 207 của Bộ luật Hàng hải 1990. Tuy nhiên, nghĩa vụ này chỉ được áp dụng riêng cho quan hệ bảo hiểm hàng hải. Do các hoạt động 
hàng hải mang tính quốc tế cao, cho nên, từ việc đã nghiên cứu kinh nghiệm của nhiều nước trên thế giới, các nhà soạn thảo Bộ luật Hàng hải đã đưa những nội dung của Bộ luật hòa nhập và thống nhất với các nước trên thế giới [13]. Cụ thể theo Điều 204 của Bộ luật Hàng hải quy định: "Người được bảo hiểm có nghĩa vu cung cấp cho người bảo hiểm biết tất cả các thông tin mà mình biết hoặc cần thiết phải biết liên quan đến việc ký kết hợp đồng bảo hiểm, có thể ảnh hương đến việc xác định khả năng xảy ra hiểm họ hoạc quyết định của nguời bảo hiểm về việc nhận bảo hiểm và các điều kiện bảo hiểm, trù loại thông tin mà mọi người đều biết hoặc nguời bảo hiểm đã biết hoặc cần phải biết".

Đến BLDS 1995, hoạt động bảo hiểm nói chung được đề cập trong BLDS và quy định về trách nhiệm cung cấp thông tin được quy định một cách chung nhất tại Điều 577, áp dụng cho mọi loại hình bảo hiểm, bao gồm cả bảo hiểm hàng hải. Tuy nhiên, BLDS lại được xây dựng theo hướng hoàn toàn khác biệt với quy định tại BLHH. Điểm khác biệt lớn nhất là ở tính tự nguyện và tính đầy đủ của trách nhiệm. Nếu như trách nhiệm theo BLHH xác định người mua bảo hiểm phải tự nguyện cung cấp mọi thông tin liên quan mà mình biết cho DNBH thì theo BLDS 1995, BMBH chỉ cần thụ động cung cấp các thông tin mà DNBH yêu cầu: "theo yêu cầu của bên bảo hiểm, BMBH phải cung cấp cho DNBH đầy đủ các thông tin có liên quan đến đối tuợng bảo hiểm, trù các thông tin mà bên bảo hiểm đã biết hoặc phải biết".

Vào những năm 1999, hoạt động của thị trường bảo hiểm Việt Nam đã có phần sôi động hơn so với nhiều năm trước, đặc biệt là đã có sự tham gia của các DNBH nhân thọ lớn trên thế giới như AIA, Prudential, Manulife.... Sự tham gia thị trường bảo hiểm Việt Nam của các DNBH giàu kinh nghiệm mang vào Việt Nam những hợp đồng mẫu, trong đó làm rõ trình tự, thủ tục để các bên xem xét ký kết HĐBH. Vấn đề trách nhiệm cung cấp thông tin trở thành một nghĩa vụ ràng buộc của bên dự định tham gia bảo hiểm, và cần thiết được pháp luật quan tâm đúng mức. Chính vì vậy, Luật Kinh doanh bảo hiểm $(\mathrm{KDBH})$ ra đời năm 2000 và được sửa đổi bổ sung vào năm 2010, và năm 2019 đã quy định mới và chi tiết hơn về trách nhiệm cung cấp thông tin tại các Điều 17, 18, 19. Cụ thể, tại điểm $\mathrm{b}$, khoản 2, Điều 18 Luật KDBH có nội dung gần tương tự với khoản 1, Điều 577 BLDS 1995, quy định về việc cung cấp theo yêu cầu của DNBH. Trong khi đó, tại khoản 1 , Điều 19 Luật KDBH quy định về một pham vi trách nhiệm gần như không có giới hạn của người mua bảo hiểm " $B M B H$ có trách nhiệm cung cấp đầy đủ thông tin liên quan đến đối tương bảo hiểm cho DNBH'. BLDS 2005 ra đời thay thế cho BLDS 1995, trong đó tại khoản 1, Điều 573 BLDS 2005, trách nhiệm cung cấp thông tin cũng được đề cập đến, cụ thể: "Khi giao kết hợp đồng bảo hiềm, theo yêu cầu của bên mua bảo hiểm, bên mua bảo hiểm phải cung cấp cho bên bảo hiểm đầy đủ thông tin có liên quan đến đối tuợng bảo hiểm, trù̀ thông tin mà bên bảo hiểm đã biết hoặc phải biết". Quy định này liên quan đến nghĩa vụ tiền hợp đồng, tuy nhiên quy định này mới chỉ áp đặt nghĩa vụ thông tin cho BMBH trong khi chưa quy định về nghĩa vụ tương ứng của $\mathrm{DNBH}$, đồng thời việc quy định loại trừ "thông tin mà bên bảo hiểm đã biết hoạc phải biết" có phần gây lúng túng cho DNBH. Tiếp đến, BLDS 2015 đã bỏ đi các quy định chuyên biệt về $\mathrm{HĐBH,} \mathrm{gồm} \mathrm{cả}$ trách nhiệm cung cấp thông tin, vì Luật kinh doanh bảo hiểm $(\mathrm{KDBH}) 2000$, sau đó được sửa đổi bổ sung 2010, và 2019 đã được xem là luật chuyên ngành, điều chỉnh riêng biệt quan hệ pháp luật bảo hiểm, trong đó nghĩa vụ cung câp thông tin của các bên đã được quy định cụ thể tại các Điều $17,18,19$ nói trên.

Đối với lĩnh vực bảo hiểm hàng hải, Bộ luật Hàng hải 2005 (tại Khoản 1, Điều 229) và sau đấy là Bộ luật Hàng hải 2015 (khoản 1, Điều 308) hiện có hiệu lực, tiếp tục giữ quan điểm về nghĩa vụ của $\mathrm{BMBH}$ phải cung cấp thông tin biết hoặc phải biết của BMBH cho DNBH. Cụ thể Bộ luật Hàng hải 2015 quy định: "Người được bảo hiểm có nghĩa vu cung cấp cho người bảo hiểm biết tất cả thông tin mà mình biết hoạc phải biết liên quan đến việc giao kết hợp đồng bảo hiểm có thể ảnh huởng đến việc xác định khả năng xảy ra rủi ro hoặc quyết định của người bảo hiểm về việc nhận bảo hiểm và 
các điều kiện bảo hiểm, trù thông tin mà mọi người biết hoặc người bảo hiểm đã biết hoạc phải biết." [14, khoản 1, Điều 308].

Nhận định có sự khác nhau trong quy định về trách nhiệm cung cấp thông tin của $\mathrm{BMBH}$ cho DNBH trong hai văn bản pháp luật về $\mathrm{KDBH}$ và bảo hiểm hàng hải, tác giả lý giải cho việc luật định khác nhau này dựa trên cơ sở phân loại bảo hiểm và mức độ áp đặt nghĩa vụ tương ứng với từng loại hình. Theo đó, các nước có xu hướng phân thành hai loại hình sản phẩm bảo hiểm: loại hình sản phẩm bảo hiểm mang tính kinh doanh (tức người mua bảo hiểm cho các đối tượng bảo hiểm phục vụ cho hoạt động sản xuất kinh doanh như bảo hiểm hàng hải, hay bảo hiểm trách nhiệm nghề nghiệp), và loại thứ hai là các sản phẩm bảo hiểm cho mục đích tiêu dùng cá nhân (như bảo hiểm nhân thọ, bảo hiểm vật chất cho các tài sản cá nhân...). Đối với loại hình bảo hiểm kinh doanh, không ai khác ngoài $\mathrm{BMBH}$ nắm rõ được các thông tin và rủi ro về đối tượng được bảo hiểm trong quá trình hoạt động thông thường, nên gánh nặng về việc cung cấp thông tin đặt lên phía $\mathrm{BMBH}$, chứ không phải DNBH. Trong khi đó đối với các sản phẩm bảo hiểm mang tính tiêu dùng, $\mathrm{BMBH}$ không được xem là bên hoàn toàn nắm giữ các thông tin về đối tượng được bảo hiểm, và những rủi ro có thể xảy ra đối với đối tượng được bảo hiểm, khi làm phép so sánh với DNBH, một đơn vị hoạt động chuyên nghiệp, có khối lượng dữ liệu lớn liên quan đến sản phẩm bảo hiểm dự kiến tiến hành, có kinh nghiệm trong việc đánh giá rủi ro đối với loại sản phẩm bảo hiểm này sẽ có thể tính toán và đo lường mức độ, tần suất rủi ro và đánh giá các loại thông tin nào cần thiết phải được cung cấp bởi $\mathrm{BMBH}$. Tất nhiên, vấn đề này cần được các nhà làm luật lưu tâm và đưa ra các quy định minh bạch hơn về phạm vi áp dụng đối với nghĩa vụ cung cấp thông tin trong các sản phẩm bảo hiểm khác nhau trong tương lai ở Việt Nam.

\section{Bình luận trách nhiệm cung cấp thông tin trong thực tiễn tranh chấp bảo hiểm ở Việt Nam}

Đối tương và phạm vi thông tin phải cung cấp
Theo quy định tại điểm $\mathrm{b}$, khoản 2, Điều 18 Luật KDBH hiện hành, quy định về thông tin mà $\mathrm{BMBH}$ có nghĩa vụ cung cấp cho $\mathrm{DNBH}$, theo đó, BMBH có nghĩa vu kê khai đầu đủ, trung thưc mọi chi tiết có liên quan đến hợp đồng bảo hiểm theo yêu cầu của $D N B H$. Sở dĩ, pháp luật quy định $\mathrm{BMBH}$ phải cung cấp thông tin theo yêu cầu của $\mathrm{DNBH}$ như trên là xuât phát từ đặc thù của hoạt động kinh doanh bảo hiểm là hoạt động yêu cầu chủ thể kinh doanh phải có sự am hiểu nhất định về lĩnh vực bảo hiểm, sản phẩm bảo hiểm, đối tượng bảo hiểm $[15,134]$.

Nếu BMBH không có những hiểu biết nhất định về đối tượng yêu cầu bảo hiểm thì $\mathrm{DNBH}$ không thể nhận biết được các rủi ro có thể xảy ra với đối tượng được bảo hiểm và nhận sự hoán chuyển rủi ro từ $\mathrm{BMBH}$, để đảm bảo bồi thường tổn thất khi những rủi ro xảy ra. Trên thực tế, việc cung cấp thông tin của $\mathrm{BMBH}$ thường thông qua giấy/đơn yêu cầu bảo hiểm. Ví dụ thông tin quan trọng và đáng chú ý trong đơn yêu cầu bảo hiểm nhân thọ là tình trạng sức khỏe của người được bảo hiểm, bởi vì đây là những thông tin mà dựa vào đó $\mathrm{DNBH}$ đánh giá để đưa ra kết luận có chấp nhận bảo hiểm hay không và cơ sở tính phí bảo hiểm. Các tranh chấp trên thực tế đa phần xuất phát từ thông tin liên quan đến tình trạng sức khỏe của người được bảo hiểm trong bảo hiểm nhân thọ.

Cũng liên quan đến việc cung cấp thông tin của BMBH, cụ thể tại khoản 1, Điều 19 Luật KDBH quy định khi giao kết hợp đồng bảo hiểm thì $\mathrm{BMBH}$ có trách nhiệm cung cấp đầy đủ thông tin liên quan đến đối tượng bảo hiểm cho DNBH. Liệu phạm vi yêu cầu thông tin của hai quy định có khác biệt nhau khi điểm $b$, khoản 2, Điều 18 Luật KDBH quy định BMBH phải cung cấp thông tin theo yêu cầu của DNBH, trong khi đó khoản 1, Điều 19 Luật KDBH quy định cung cấp đầy đủ các thông tin liên quan đến đối tượng bảo hiểm. Như vậy, trong trường hợp này $\mathrm{BMBH}$ chỉ cung cấp trong phạm vi của đơn yêu cầu bảo hiểm đã đảm bảo đầy đủ những thông tin liên quan đến đối tượng bảo hiểm mà chưa được quy định trong đơn yêu cầu bảo hiểm không? Có những trường hợp $\mathrm{BMBH}$ có những thông tin quan 
trọng mà DNBH chưa yêu cầu cung cấp, hậu quả của việc này tạo sự bất lợi cho DNBH đánh giá rủi ro và khi sự kiện bảo hiểm xảy ra. Ví dụ cho trường hợp này, vào thời điểm giao kết $\mathrm{HĐBH}$, người được bảo hiểm hoàn toàn khỏe mạnh, bình thường nhưng do có thói quen uống rượu. Việc thường xuyên uống rượu là một căn cứ quan trọng đối với $\mathrm{DNBH}$ trong việc đánh giá rủi ro và căn cứ để xác định lại phí bảo hiểm. Ngược lại, BMBH mặc dù không cung cấp thông tin này nhưng cũng không vi phạm nghĩa vụ cung cấp thông tin bởi vì $\mathrm{DNBH}$ không yêu cầu.

Một vấn đề nữa cũng liên quan đến nghĩa vụ cung cấp thông tin của BMBH tại điểm $b$, khoản 2 , Điều 18 đó chính là cụm từ "moi chi tiết có liên quan đến $H Đ B H$ ”. Với cách quy định như vậy, có thể thấy được đối tượng và pham vi thông tin được quy định chưa thực sự thống nhất và rõ ràng (mọi chi tiết nhưng theo yêu cầu của DNBH) $[16,55]$.

Thực tiễn xét xử, Tòa án đã có quan điểm cho vấn đề này thông qua bản án Số 313/2016/DS-PT ngày 16/03/2016 về tranh chấp hợp đồng bảo hiểm [17]. Trong vụ việc này, phía công ty bảo hiểm cho rằng tại câu hỏi số 54 Đơn yêu cầu bảo hiểm ngày 25/3/2009:

"Loét đường tiêu hóa, xuất huyết tiêu hóa, viêm tuy, viêm kiết tràng, khó tiêu thuờng xuyên, khó nuốt, hoặc rối loạn tại dạ dày, ruột gan hoạc túi mật?" bà $\mathrm{H}$ (người được bảo hiểm) đánh dấu vào ô không (nghĩa là bà $\mathrm{H}$ khai không bị rối loạn dạ dày) trong khi bà $\mathrm{H}$ bị đau dạ dày là khai báo không trung thực, cụm từ rối loạn tai dạ dày bao gồm tất cả các bệnh liên quan đến dạ dày trong đó có bệnh đau dạ dày.

Quan điểm của Tòa án cho rằng có sự khác nhau giữa "rối loạn dạ dày" trong câu hỏi và căn bệnh "đau dạ dày" trên thực tế của bà $H$. Tòa án xét xử theo hướng đối tượng của nghĩa vụ cung cấp cấp thông tin phải nằm trong câu hỏi của DNBH. Tòa án còn viện dẫn thêm quy định tại khoản 2, Điều 407 trong BLDS 2005 về trường hợp "hợp đồng dân sụ theo mẫu có điều khoản không rõ ràng thì bên đưa ra hơp đồng theo mẫu phải chịu bất lợi khi giải thich diều khoản đó." cùng với Điều 21 Luật $\mathrm{KDBH}$ quy định giải thích theo hướng có lợi cho người mua bảo hiểm trong trường hợp HĐBH có điều khoản không rõ ràng. Như vậy, những nội dung mà không được đề cập trong Đơn yêu cầu bảo hiểm thì sẽ không thuộc đối tượng của nghĩa vụ cung cấp thông tin của $\mathrm{BMBH}$ hay nói cách khác, BMBH chỉ phải cung cấp các thông tin mà $\mathrm{DNBH}$ yêu cầu.

Tính không trung thưc của thông tin

Tính trung thực của thông tin trong $\mathrm{HĐBH}$ là yếu tố quan trọng khi giao kết $\mathrm{HĐBH.} \mathrm{Trên}$ thực tiễn, các tranh chấp về HĐBH đa phần xuất phát từ việc $\mathrm{DNBH}$ cho rằng $\mathrm{BMBH}$ đã cố ý cung cấp thông tin không đúng sự thật, từ đó từ chối chi trả quyền lợi cho $\mathrm{BMBH}$. Khi xảy ra tranh chấp BMBH cũng đưa ra lập luận cho rằng bản thân mình không biết những thông tin đó hoặc nếu cố tình che giấu thông tin thì cũng lập luận theo hướng lừa dối để yêu cầu Tòa án tuyên HĐBH vô hiệu. Cụ thể, theo một Tòa án, "xét trước khi ký hơp đồng bảo hiểm nhân tho vơi Công ty Manulife, ông Ngoc đã tùng khám bệnh theo bảo hiểm y tế tại Bệnh viện Nguyễn Trãi và được bác sĩ của Công ty manulife khám bệnh cũng nhu kiểm tra sức khỏe tại Trung tâm Hòa hảo nhưng đều không biết ông Ngọ bi bệnh lao não. Xét các triệu chưng bệnh của ông Ngoc khi khám bệnh tại Bệnh viên Nguyễn Trãi nhu: chóng mặt, nhưc đầu là bệnh thuoòng xuyên của con người, việc ông Ngọc không khai khi kiểm tra súc khỏe không phải là ông Ngọc biết bệnh lao não nhung giấu không khai. Xét trong hơp đồng bảo hiềm nhân tho giũa Công ty Manulife và ông Ngọc không quy định nêu ngườ ký hơp đồng khai sai nhũng điểm trong phiếu kiểm tra súc khỏe thì không được thanh toán quyền lợi bảo hiểm. Do đó, Công ty Manulife đã ký hợp đồng bảo hiểm với ông Ngọc thi Công ty Manulife phải trả cho bà Liên (người đại diện của ông Ngọc) quyền lợi bảo hiểm của ông Ngọc" [18].

Như vậy, theo nhận định của Tòa án trong bản án này có thể hiểu, bệnh lao não của ông Ngọc là có thật và việc này không được ông Ngọc khai báo khi xác lập HĐBH nhân thọ là không vi phạm bởi vì trường hợp này ông Ngọc không hề biết trong người ông đang có căn bệnh lao não theo nhận định Tòa án. 
Qua bản án này có thể thấy rằng, để xác định tính không trung thực của thông tin cho phép DNBH từ chối thanh toán tiền bảo hiểm, đó phải là thông tin mà $\mathrm{BMBH}$ biết nhưng không kê khai. Trong trường hợp này, ông Ngọc không biết về thông tin bệnh lao não, vậy DNBH không thể từ chối thanh toán tiền bảo hiểm cho ông Ngọc. Do đó, việc biết và không công khai là hai thành tố quan trọng trong việc xác định tính không trung thực của thông tin. Đối chiếu với quy định của pháp luật kinh doanh bảo hiểm thì hiển tại, Luật KDBH mới chỉ quy định các bên có nghĩa vụ cung cấp thông tin một cách trung thực nhưng chưa quy định cụ thể các trường hợp có thể loại trừ.

Chế tài không đồng nhất đối với việc vi phạm nghĩa vu cung cấp thông tin

Đối với hành vi vi phạm nghĩa vụ cung cấp thông tin, Luật KDBH hiện hành quy định các biện pháp xử lý khác nhau như hợp đồng có thể bị đình chỉ, bị hủy bỏ hoặc bị vô hiệu. Theo khoản 2, Điều 19 Luật KDBH quy định: "Doanh nghiệp bảo hiểm có quyền đơn phương đình chi thực hiện hợp đồng bảo hiểm và thu phí bảo hiềm đến thời điểm đình chỉ thưc hiện hợp đồng bảo hiểm khi bên mua bảo hiểm có một trong nhũng hành vi sau đây: a) Có ý cung cấp thông tin sai sư thật nhằm giao kết hợp đồng bảo hiểm để được trả tiền bảo hiểm hoạc được bồi thuòng; b) Không thưc hiện các nghĩa vu trong việc cung cấp thông tin cho doanh nghiệp bảo hiểm theo quy định tại điểm $c$ khoản 2 Điều 18 của Luật này”.

Mặc khác, tại điểm d, khoản 1, Điều 22 của Luật này quy định về trường hợp $\mathrm{HĐBH}$ vô hiệu khi $\mathrm{BMBH}$ hoặc $\mathrm{DNBH}$ có hành vi lừa dối khi giao kết HĐBH. Khi đó, DNBH sẽ hoàn trả lại phí bảo hiểm mà bên mua bảo hiểm đã đóng trước đó, và không phát sinh trách nhiệm chi trả số tiền bảo hiểm hay số tiền bồi thường cho BMBH.

Vậy, liệu hành vi cố ý cung cấp thông tin sai sự thật nhằm giao kết hợp đồng bảo hiểm có phải là một hành vi lừa dối?

Tại Điều 127, BLDS 2015 cũng định nghĩa về hành vi lừa dối trong giao dịch dân sự, theo đó: "Lừa dối trong giao dịch dân sự là hành vi cố ý của một bên hoặc của người thứ ba nhằm làm cho bên kia hiểu sai lệch về chủ thể, tính chất của đối tượng hoặc nội dung của giao dịch dân sự nên đã xác lập giao dịch đó.". Qua quy định trên có thể hiểu một hành vi được xem là lừa dối khi: Thứ nhất, đưa ra thông tin sai lệch về chủ thể, đối tượng hoặc nội dung của giao dịch dân sự đó; Thứ hai, bản thân người đưa ra thông tin biết rõ rằng thông tin đó là sai lệch sự thật với chủ ý làm cho người nghe tin vào thông tin đó; Thứ ba, người nhận thông tin đã tin tưởng vào thông tin đó nên giao kết hợp đồng.

Như vậy, có thể thấy hành vi cố ý cung cấp thông tin sai sự thật nhằm giao kết hợp đồng bảo hiểm để được trả tiền bảo hiểm hoặc được bồi thường thường theo như quy định tại điểm a, khoản 2, Điều 19 của Luật $\mathrm{KDBH}$ là một dạng hành vi lừa dối. Tuy nhiên, Luật $\mathrm{KDBH}$ cung cấp hai chế tài với hai hậu quả pháp lý hoàn toàn khác nhau đối với cùng một hành vi cố ý cung cấp thông tin sai sự thật. Đối với chế tài $\mathrm{DNBH}$ có quyền đơn phương đình chỉ thực hiện hợp đồng và thu phí đến thời điểm đình chỉ thực hiện hợp đồng, quy định này có nghĩa là cho đến thời điểm đình chỉ thực hiện, $\mathrm{HĐBH}$ vẫn có giá trị pháp lý và chỉ bị triệt tiêu trong tương lai. Mặt khác, đối với hành vi lừa dối, hậu quả pháp lý là HĐBH bị tuyên vô hiệu mà mỗi bên sẽ hoàn trả lại cho nhau những gì đã nhận (căn cứ theo quy định tại Điều 131, BLDS 2015). Trên thực tế, có một số DNBH xây dựng điều khoản mẫu HĐBH theo quy định tại khoản 2, Điều 19 Luật KDBH, điển hình là như trường hợp của Công ty Prudential Việt Nam theo hướng hoàn phí bảo hiểm khi $\mathrm{BMBH}$ vi phạm nghĩa vụ cung cấp thông tin, xem xét một điều khoản trong Quy tắc sản phẩm bảo hiểm của Công ty:

Điều 11.2 a), ii) Nghĩa vụ của Bên mua bảo hiểm và Người được bảo hiểm:

a. Kê khai chính xác thông tin cần thiết

ii. Nếu bên mua bảo hiểm/Người được bảo hiểm cố ý kế khai không đầy đủ, chính xác và trung thực các thông tin cần thiết theo yêu của Prudential, theo đó, nếu với thông tin chính xác, Prudential sẽ không chấp nhận bảo hiểm, Prudential không có trách nhiệm chi trả các quyền lợi bảo hiểm và có quyền đơn phương đình chỉ Hợp đồng bảo hiểm này ngay sau khi 
phát hiện ra hành vi vi phạm của bên mua bảo hiểm và chỉ trả cho bên mua bảo hiểm Giá trị quỹ của hợp đồng tại Ngày định giá kế tiếp ngay sau khi Hợp đồng bảo hiểm bị đình chỉ sau khi trừ đi chi phí khám sức khỏe, cá Quyền lợi đã chi trả hoặc chấp thuận chi trả hoặc đã chi trả các Khoản nợ, nếu có, tính đến ngày đình chỉ Hợp đồng bảo hiểm.

Một số DNBH khác lựa chọn việc vô hiệu HĐBH ngay từ đầu hay hủy bỏ HĐBH khi có sự vi phạm nghĩa vụ cung cấp thông tin, ví dụ như điều khoản HĐBH trong bản án được lựa chọn làm án lệ số 22/2018/AL: "Nếu bất cú thông tin nào bên mua bảo hiểm hoặc người được bảo hiểm cung cấp cố ý che giấu hoạc khai báo sai sư thật làm ảnh hưởng nghiêm trọng đến quyết định đánh giá chấp nhận bảo hiếm thì công ty có thể hưy bỏ hợp đồng và hợp đồng không có hiệu lực ngay tù đầu".

Dù có sự không đồng nhất trong cách quy định chế tài trong $\mathrm{HĐBH}$ hay quy tắc sản phẩm bảo hiểm, tuy nhiên, tất cả những cách xây dựng quy định trên đều được Bộ Tài chính chấp thuận phê chuẩn trong các quy tắc sản phẩm bảo hiểm của $\mathrm{DNBH}$ và cho phép $\mathrm{DNBH}$ tiến hành kinh doanh trên thực tiễn.

Cũng chính vì quy định của Luật $\mathrm{KDBH}$ chưa rõ ràng về vấn đề này, và việc áp dụng pháp luật trên thực tiễn quá đa dạng, nên việc xét xử Tòa án đóng vai trò quan trọng để cung cấp giải pháp hợp lý công bằng cho các bên trong quan hệ bảo hiểm. Giải pháp được đa số Tòa án lựa chọn thông qua thực tiễn giải quyết tranh chấp là tuyên hợp đồng vô hiệu nên $\mathrm{DNBH}$ phải hoàn lại phí bảo hiểm mà $\mathrm{BMBH}$ đã nộp, và $\mathrm{DNBH}$ không phát sinh trách nhiệm bồi thường hay chi trả số tiền bảo hiểm. Cụ thể, theo một bản án vào năm 2007 của Tòa án nhân dân TP.Hồ Chí Minh, "tại thời điểm ông Hùng lập thủ tục yêu cầu bảo hiểm, ông Hùng đã có bệnh tăng huyết áp nhung ông Hùng không khai đầy đủ vào hồ so mua bảo hiểm tình trạng tăng huyết áp của mình đúng nhu thỏa thuận tại Điều 3.1 của $H Đ B H$ mà hai bên đã ký. Theo quy định tại khoản 1, Điều 573 BLDS 2005 thi khi giao kết $H Ð B H$, theo yêu cầu của bên bảo hiểm, BMBH phải cung cấp cho bên bảo hiểm đầy đủ thông tin có liên quan đến đối tuợng được bảo hiểm, trù̀ thông tin mà bên bảo hiểm đã biết hoạc phải biết" nên HĐBH số 05000009806008UL-A ngày 29/06/2006 đươc xác lạp giữa ông Hùng với Công ty $A C E$ là vô hiệu tù thờ điểm ký kết...Do HĐBH vô hiệu nên không làm phát sinh, thay đổi, chấm dưt quyền, nghĩa vu của các bên kể tù thời điểm xác lạp, các bên khôi phục lại tình trạng ban đầu, hoàn trả cho nhau nhũng gì đã nhận..." [19].

Qua thực tiễn tranh chấp bảo hiểm, có thể nhận thấy một điểm chung rằng việc cung cấp thông tin sai đa phần đều xuất phát từ thời điểm giao kết hợp đồng bảo hiểm. Nếu nguyên nhân dẫn đến tranh chấp tồn tại trong giai đoạn tiền hợp đồng bảo hiểm lại được xử lý bằng giải pháp“đình chî", tức là vẫn giữ lại quá khứ của hợp đồng và chỉ làm mất giá trị trong tương lai của hợp đồng có tạo ra sự hợp lý không? Trong khi đó, nếu theo hướng vô hiệu HĐBH thì các bên trong quan hệ $\mathrm{HĐBH}$ sẽ quay trở lại thời điểm trước khi giao kết HĐBH.

Từ những phân tích trên, một vấn đề được đặt ra là với cùng một hành vi là cố ý cung cấp thông tin sai sự thật của bên mua bảo hiểm thì khi nào thì nên áp dụng quy định tại khoản 2 , Điều 19 của Luật KDBH, khi nào áp dụng quy định tại điểm $\mathrm{d}$, khoản 1 , Điều 22 để giải quyết? Có nên thống nhất hướng giải quyết bằng việc tuyên HĐBH theo hướng vô hiệu để thống nhất trong xét xử? Đây là những câu hỏi mà các nhà làm luật và cơ quan tư pháp cần giải đáp, để góp phần hạn chế được tình trạng tranh chấp bảo hiểm, mặc khác, khi phát sinh tranh chấp, các bên dựa vào đó có thể xác định chế tài một cách dễ dàng hơn.

DNBH hủy bỏ HĐBH nếu BMBH thông báo sai tuổi của người được bảo hiểm

Ngoài hai hậu quả pháp lý là đình chỉ hoặc tuyên vố vô hiệu như trình bày ở trên, $\mathrm{HĐBH}$ có thể bị DNBH hủy bỏ nếu BMBH thông báo sai tuổi của người được bảo hiểm. Độ tuổi là một trong những yếu tố gắn liền với tình trạng sức khỏe của mỗi người, dựa vào đó $\mathrm{DNBH}$ có thể đánh giá mức độ rủi ro, cơ sở để tính phí bảo hiểm. Người đó độ tuổi lớn phí bảo hiểm sẽ khác so với bảo hiểm cho một người có độ tuổi nhỏ hơn. Theo quy định tạ khoản 2, Điều 34 của Luật $\mathrm{KDBH}$ quy định về thông báo sai tuổi 
của người được bảo hiểm trong bảo hiểm nhân thọ, "doanh nghiệp bảo hiểm có quyền huỷ bỏ hợp đồng bảo hiểm và hoàn trả số phí bảo hiểm đã đóng cho bên mua bảo hiểm sau khi đã trù các chi phi hơp lý có liên quan, truờng hợ hợp đồng bảo hiểm đã có hiệu lực tù hai năm trở lên thi doanh nghiệp bảo hiểm phải trả cho bên mua bảo hiểm giá tri hoàn lai". Qua quy định này có thể hiểu HĐBH vẫn có hiệu lực pháp lý cho đến khi HĐBH bị hủy bỏ bởi DNBH.

Tuy nhiên, BLDS 2015 tại Điều 427 quy định về hậu quả pháp lý của việc hủy bỏ hợp đồng, thì khi hợp đồng bị hủy bỏ đồng nghĩa với việc hợp đồng không có hiệu lực từ thời điểm giao kết, các bên không phải thực hiện nghĩa vụ đã thỏa thuận. Trái ngược với quy định trong BLDS 2015, trong Luật KDBH quy định HĐBH bị hủy bỏ nhưng DNBH vẫn phải hoàn trả lại giá trị hoàn lại của $\mathrm{HĐBH}$ cho BMBH. Do vậy, quy định trong Luật KDBH có sự mâu thuẫn, chưa có sự thống nhất với việc xử lý hợp đồng bị hủy bỏ theo quy định của BLDS 2015. Để tạo sự thống nhất với quy định trong BLDS 2015, thiết nghĩ Luật KDBH nên có phương hướng giải quyết để phù hợp với trong BLDS 2015.

Cũng tại quy định này, "giá trị hoàn lại" được đề cập nhưng chưa có quy định giải thích và hướng dẫn thực hiện. Trên thực tiễn, giá trị hoàn lại thường chỉ quy định trong Bộ quy tắc và Điều khoản của $\mathrm{DNBH}$, điều này gây ra không ít bối rối cho BMBH. Cụ thể: "trường hơp của chị $H$ (Nha Trang) hoàn toàn bất ngò̀ khi nhận được một số tiền hoàn lại là 1,3 triệu đồng khi chi đề nghi chấm dưt hơp đồng trong khi tổng số phí chị đóng trong 21 tháng qua là 3,5 triệu đồng" $[20,85]$. Giá trị hoàn lại trong trường hợp này nhỏ rất nhiều so với số tiền phí bảo hiểm mà chị đã đóng. Như vậy, để thống nhất cũng như có cơ sở để $\mathrm{BMBH}$ có thể dựa vào đó có thể xác định được giá trị hoàn lại, mặc khác vừa để đảm bảo quyền lợi của $\mathrm{BMBH}$, tránh trường hợp DNBH quy định bất lợi cho BMBH.

Tóm lại, qua thực tiễn hoạt động bảo hiểm ở Việt Nam, các vụ tranh chấp liên quan đến việc cung cấp thông tin của các bên trong quan hệ bảo hiểm ngày càng gia tăng đáng kể. Việc tìm hiểu bản chất bất cân xứng thông tin trong quan hệ tiền hợp đồng bảo hiểm và các quy định pháp luật về trách nhiệm cung cấp thông tin, đồng thời chỉ ra các khiếm khuyết của luật viết và nhu cầu hoàn thiện các quy định này là những việc cần thiết và quan trọng. Những nội dung nghiên cứu trong bài viết mong muốn góp phần cung cấp cơ sở lý luận, định hướng hoàn thiện quy định pháp luật có liên quan, và cung cấp giải pháp pháp lý cho việc giải quyết các tranh chấp phát sinh trong thực tiễn hoạt động bảo hiểm liên quan đến trách nhiệm cung cấp thông tin.

\section{Tài liệu tham khảo}

[1] Roger Brownsword, Norma J. Hird, Geraint Howells, 1999, Good faith in Contract: concept and context, NXB. Dartmouth Pub Co.

[2] Rodrigo Novoa, 2005, "Culpa in contrahendo: a comparative law study: Chilean law and the United Nations Convention on contracts for the international sales of goods (CISG)", Arizona Journal of international and Comparative law, Vol.22 .No.3. 91; và Anil Ozturk, 2017, "The Conceptual Analysis of 'Culpa in Contrahendo': A Critical Study in EU Private International Law", LL.M Thesis, School of Law, The University of Dublin, Trinity College.

[3] Rolger Halson, 2013, Contract law, 2th ed, Paula Giliker University of Bristol.

[4] Bản thuyết minh dự thảo Bộ luật Dân sự 2015.

[5] Bộ luật Dân sự 2005.

[6] Bộ luật Dân sự 2015.

[7] Từ điển Tiếng Việt Soha:

[8]

http://tratu.soha.vn/dict/vn_vn/Thi\%E1\%BB\%87 n_ch\%C3\%AD, truy cập ngày 26/06/2020.

[9] Lê Trường Sơn, 2016, Giai đoạn tiền hợp đồng trong pháp luật Việt Nam, NXB. Hồng Đức - Hội Luật gia Việt Nam.

[10] Đỗ Văn Đại, 2018, "Một số vấn đề pháp lý phát sinh trong thực tiễn về bảo hiểm nhân thọ", Tạp chi Khoa hoc pháp lý, số 07(119)/2018.

[11] Phán quyết vụ án Carter v Boehm (1766) 3 Burr 1905: 
[12] http://pryan2.kingsfaculty.ca/pryan/assets/File/W atterson_2008_on_Carter_v_Boehm_1766.pdf, truy cập ngày 26/06/2020.

[13] Đạo Luật bảo hiểm hàng hải Anh 1906 (Marine insurance Act 1906).

[14] Luật bảo hiểm Pháp 1967 (Code des Assurance), toàn văn tại http://codes.droit.org/CodV3/assurances.pdf, truy cập ngày 26/06/2020.

[15] Phạm Sĩ Hải Quỳnh, 2004, “Cơ sở hình thành nghĩa vụ cung cấp thông tin trong giao kết hợp đồng bảo hiểm", Tạp chí Khoa hoc pháp lý, số $3 / 2004$, toàn văn bài viết có thể truy cập tại https://thongtinphapluatdansu.edu.vn/2008/01/30/ 423546/, truy cập ngày 26/06/2020.
[16] Bộ luật Hàng hải 2015.

[17] Bản án được Hội đồng Thẩm phán Tòa án nhân dân tối cao quyết định ban hành thành Án lệ số 22/2018/AL được Hội đồng Thẩm phán Tòa án nhân dân tối cao thông qua ngày 17 tháng 10 năm 2018 và được công bố theo Quyết định số 269/QĐ-CA ngày 06 tháng 11 năm 2018 của Chánh án Tòa án nhân dân tối cao.

[18] Bản án số 1966/DS-ST ngày 10/09/2004 của Tòa án nhân dân TP. Hồ Chí Minh.

[19] Bản án số 598/2007/DS-PT ngày 07/06/2007 của Tòa án nhân dân TP.Hồ Chí Minh.

[20] Trần Vũ Hải, 2006, Hợp đồng bảo hiểm nhân thọ - Những vấn đề lý luận và thực tiễn, NXB.Tư pháp, Hà Nội. 